\title{
Achalasia complicated by oesophageal squamous cell carcinoma: a prospective study in 195 patients
}

\author{
M A C Meijssen, H W Tilanus, M van Blankenstein, W C J Hop, G L Ong
}

\begin{abstract}
To determine the incidence of oesophageal carcinoma in patients with achalasia and to establish the efficacy of endoscopic surveillance, 195 consecutive patients with achalasia (90 men and 105 women, mean age 52 years), who were treated by pneumatic dilatation in our institution between 1973 and 1988 were prospectively studied. None of the patients had undergone cardiomyotomy. Follow up totalled 874 person years after pneumatic dilatation. In this period three patients developed an oesophageal squamous cell carcinoma. The mean age at diagnosis of the oesophageal carcinoma was 68 years $(37,77$, and 89 years). The mean period between the onset of dysphagia and the diagnosis of the tumour was 17 years $(19,28$, and 5 years); the mean interval between the diagnosis of achalasia and carcinoma was 5.7 years $(5,8$, and 4 years). The incidence of oesophageal squamous cell carcinoma in this series (3.4/1000 patients per year) is significantly higher than the statistically expected incidence $(0 \cdot 104 / 1000$ patients per year) using age and sex specific incidence data from the population of the Netherlands (Poisson statistics: $\mathbf{p}<\mathbf{0 . 0 0 1}$ ). The risk of developing oesophageal squamous cell carcinoma in patients with achalasia is therefore increased 33 fold. Periodic endoscopy showed the potential for detecting early stage oesophageal carcinoma in two cases but a larger study with a longer follow up is required to determine the efficacy of endoscopic screening in improving the prognosis for patients with achalasia who develop oesophageal squamous cell carcinoma.
\end{abstract}

The relation between achalasia and oesophageal carcinoma was first reported by Fagge in 1872.' Since this initial observation, several case reports and retrospective reviews have been published to substantiate the validity of this relation. An increased risk of developing oesophageal carcinoma in patients with long standing aschalasia has been reported by several authors, with incidences varying widely from 1.7 to $20 \%$. $^{2-18}$ This was not confirmed, however, in a prospective study by Chuong et al, who found no case of carcinoma in 91 patients with achalasia followed up over 6.5 years. ${ }^{19}$

By the time symptoms of carcinoma of the oesophagus are evident over and above the dysphagia of achalasia, the tumour is usually advanced. This is because symptoms of carcinoma resemble those of the underlying achalasia and because the tumour has to be large to obstruct a dilated oesophagus. Consequently, the prognosis in these patients is poor: $80 \%$ of patients with achalasia and oesophageal carcinoma have been found unsuitable for oesophageal resection, against $50 \%$ of non-achalasia patients with an oesophageal carcinoma. ${ }^{1520}$ The earlier the oesophageal carcinoma is diagnosed, the greater the chances of three year survival after resection. The three year survival after resection for patients with a stage I or II oesophageal squamous cell carcinoma is $48 \%$, whereas for patients with stage III disease it is only $25 \%$. $^{2021}$

This study aimed to determine the incidence of oesophageal squamous cell carcinoma in patients with achalasia and to establish the efficacy of long term endoscopic surveillance in detecting oesophageal carcinomas at an early, potentially curable stage. We performed a prospective study of 195 patients diagnosed as having achalasia between 1973 and 1988 and subsequently followed them up.

Patients and methods

The study involved a cohort of 195 patients, 90 men and 105 women, in whom achalasia was diagnosed between September 1973 and January 1988. In all patients the diagnosis of achalasia was based on symptoms and confirmed by endoscopy, oesophageal manometry, and radiology (barium swallow). All patients were treated by serial pneumatic dilatation and were subsequently followed up according to a prospective protocol at 3 months, $1,2,4,7$, and 10 years or longer after the pneumatic dilatation. In none of the patients was cardiomyotomy performed. Follow up examinations consisted of oesophageal manometry, a barium swallow, and endoscopy with biopsy.

The length of follow up was calculated from the date of the first pneumatic dilatation to the date of the last follow up. Extra information was sometimes obtained from the general practitioner or from the patient by telephone.

Staging of oesophageal carcinomas was performed according to the postsurgical resection classification of malignant tumours. ${ }^{21}$

The incidence of oesophageal squamous cell carcinoma in this group of patients was compared with an age and sex matched group of the population of the Netherlands. ${ }^{22}$ For this analysis the subject-years method was applied. ${ }^{22}$ Statistical significance was established using Poisson statistics. ${ }^{23}$

\section{Results}

Achalasia was found in all age groups with a mean age of 52 years at the time of diagnosis (Figure). During the follow up period 27 patients died, one of oesophageal squamous cell 
Age and sex distribution at the time of diagnosis of achalasia in 195 patients. Patients developing oesophageal squamous cell carcinoma during the follow up are indicated.

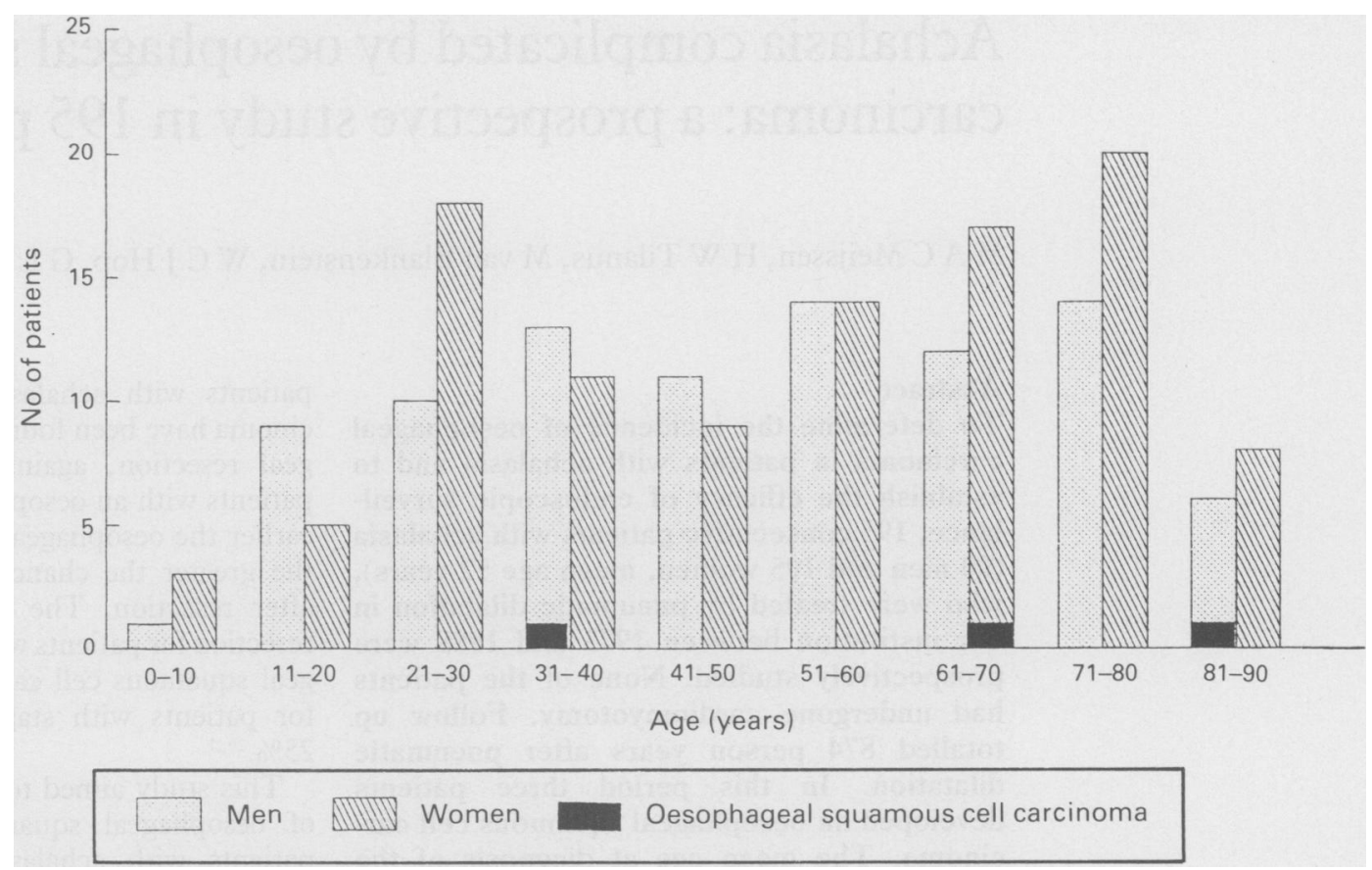

carcinoma and 26 from unrelated causes. Of the 168 surviving patients, two also developed an oesophageal squamous cell carcinoma. In these three patients the oesophageal squamous cell carcinoma was diagnosed at a mean age of 68 years $(37,77$, and 89 years respectively) and after a mean period of 17 years $(19,28$, and 5 years respectively) of dysphagia. The mean interval between the diagnosis of achalasia and carcinoma of the oesophagus was $5 \cdot 7$ years $(5,8$, and 4 years respectively).

In all three patients the oesophageal squamous cell carcinoma was located in the middle third of the oesophagus, but in one the tumour also extended to the distal part of the oesophagus.

The total follow up was 874 person years. The observed number of oesophageal squamous cell carcinoma was three, giving an incidence of oesophageal squamous cell carcinoma for this series of $3 / 874$ person years or $3 \cdot 4 / 1000$ patients per year. In an age and sex matched group of the population of the Netherlands the expected incidence of oesophageal squamous cell carcinoma is $0 \cdot 104 / 1000$ patients per year. The difference between the observed incidence in this series and the expected incidence $(3.4 v$ $0 \cdot 104)$ is statistically significant $(p<0.001)$. The increased risk of developing oesophageal squamous cell carcinoma in this group of patients with achalasia is $3 \cdot 4: 0 \cdot 104=33$ fold.

\section{CASE HISTORIES OF THE THREE PATIENTS WITH ACHALASIA AND OESOPHAGEAL SQUAMOUS CELL CARCINOMA}

\section{Case 1}

A 32 year old man was diagnosed as having achalasia after 14 years of dysphagia. He was treated by serial pneumatic dilatation after which he had regular routine examinations according to the protocol. During follow up he did not complain about dysphagia, although barium swallows and endoscopy still showed consider- able functional impairment. Routine endoscopy five years later (postponement by the patient of one year according to our protocol) was hampered by stasis of saliva and food in the elongated oesophagus. Before repeated endoscopy he complained of hoarseness. At endoscopy a paralysis of the left vocal cord and a tumour with a diameter of $2.5 \mathrm{~cm}$ at approximately $29 \mathrm{~cm}$ from the upper incisor teeth were seen. After preoperative radiotherapy the patient underwent oesophageal resection and gastric tube reconstruction. Postresection staging Paralysis of the vocal cord proved to be reversible. This temporary paralysis was probably caused by a viral infection as there were raised viral titres at the time of the hoarseness. Six years after surgery the patient is well and there are no signs of local recurrence or metastasis.

\section{Case 2}

Achalasia was diagnosed in a 69 year old woman who had suffered from dysphagia for 20 years. Treatment consisted of two series of pneumatic dilatation. After this she no longer complained of dysphagia, but radiology and endoscopy still showed some functional impairment. After eight years of routine follow up endoscopy, which was delayed for one year at her request, a superficial oesophageal squamous cell carcinoma was discovered $30 \mathrm{~cm}$ from the upper incisor teeth. Oesophageal resection with gastric tube reconstruction was undertaken. Postresection staging showed a stage I squamous cell carcinoma. Three years after surgery she is well and without signs of local recurrence or metastasis.

\section{Case 3}

A 85 year old man with achalasia underwent pneumatic dilatation after 12 months of dysphagia and vomiting. Screening at three months and one year after pneumatic dilatation showed a stage IIA squamous cell carcinoma. 
Oesophageal carcinoma (ca) complicating achalasia (review of published reports)

\begin{tabular}{|c|c|c|c|c|c|c|c|}
\hline Author & $\begin{array}{l}\text { Cases of } \\
\text { achalasia } \\
(n)\end{array}$ & $\begin{array}{l}\text { Cases of } \\
\text { carcinoma } \\
(n)\end{array}$ & $\begin{array}{l}\text { Mean } \\
\text { age } \\
(y)^{\star}\end{array}$ & $\begin{array}{l}\text { Duration of } \\
\text { dysphagia } \\
(y) t\end{array}$ & $\begin{array}{l}\text { Mid-oesophageal } \\
\text { location } \\
(\%)\end{array}$ & $\begin{array}{l}\text { Squamous } \\
\text { cell ca } \\
(\%)\end{array}$ & $\begin{array}{l}\text { Sex ratio } \\
M: F \\
(\%)\end{array}$ \\
\hline Kornblum & 33 & & 3 & 40 & $9 \cdot 5$ & 33 & 6733 \\
\hline Matthews ${ }^{3}$ & 1000 & 3 & 78 & 48 & 100 & 100 & 100 \\
\hline Camara-Lopes ${ }^{+}$ & 90 & 7 & $52 \cdot 2$ & $15 \cdot 5$ & 57 & 86 & 100 \\
\hline Ferreira-Santos & 145 & 9 & ? & $?$ & ? & ? & ? \\
\hline Barrett $^{6}$ & 120 & 7 & ? & ? & ? & ? & ? \\
\hline Belsey & 133 & 9 & ? & ? & 100 & 100 & ? \\
\hline Just-Viera ${ }^{x}$ & 148 & 5 & $47 \cdot 6$ & $21 \cdot 4$ & 60 & 100 & 100 \\
\hline Lortat-Jacob ${ }^{10}$ & 279 & 24 & $?$ & $?$ & 58 & 92 & 80 \\
\hline Pierce" & 110 & 3 & $56 \cdot 3$ & $.22 \cdot 7$ & 33 & 100 & 67 \\
\hline Carter': & 60 & 4 & $60 \cdot 3$ & $15 \cdot 3$ & 50 & 100 & 50 \\
\hline Norton $^{13}$ & 350 & 7 & 59 & ? & ? & 90 & ? \\
\hline Chuong $^{19}$ & 91 & 0 & - & - & - & - & - \\
\hline
\end{tabular}

^ Mean age at the time of diagnosis of oesophageal carcinoma.

† Mean duration of dysphagia at the time of diagnosis of oesophageal carcinoma.

showed good functional results. After one year he refused further routine examinations. Four years after pneumatic dilatation his symptoms recurred. Endoscopy showed an oesophageal squamous cell carcinoma extending from 28 to $40 \mathrm{~cm}$ from the upper incisor teeth with a deep ulcer at $30 \mathrm{~cm}$. Further analysis showed multiple metastases (stage IV). This patient was treated by palliative surgical intubation and died two months later.

\section{Discussion}

Since Fagge's first observation in $1872,{ }^{1}$ there have been several case reports and clinical studies substantiating a relation between achalasia and carcinoma of the oesophagus (Table). ${ }^{2-810-1319}$ While some authors have reported an increased risk, ${ }^{2-8810-13}$ others have not. ${ }^{19}$ Our prospective study confirms the findings of authors reporting an increased risk of oesophageal carcinoma in patients with long standing achalasia..$^{2-810-13}$ The reported incidences, however, vary widely between $1.7 \%$ and $20 \%$. This considerable variation can be explained by several factors. One is the difference in the length of follow up mentioned in the reports. ${ }^{2-914}$ Furthermore, in some reports prevalences are confused with

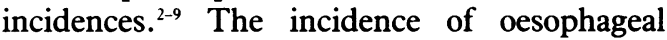
squamous cell carcinoma in our series is $3 \cdot 4 / 1000$ patients per year, which means a 33 fold increased risk of developing carcinoma of the oesophagus in comparison with a control population. Achalasia, therefore, certainly seems a high risk factor for the development of oesophageal squamous cell carcinoma.

The mean age of the patients with oesophageal squamous cell carcinoma in this series was 68 years (range $37-89$ years). This is at variance with the published reports; the reported mean age at which oesophageal squamous cell carcinoma is found in patients with achalasia is 48-51 years, which is lower than the mean age at which oesophageal carcinoma occurs in the normal population (62-67 years).$^{2+814}$ However, as the duration of dysphagia seems more important in developing oesophageal squamous cell carcinoma than the age of the patient, ${ }^{82-14}$ our results may merely reflect differences in patient populations. This is corroborated by the fact that we found a mean interval of 17 years from the onset of dysphagia to the diagnosis of oesophageal squamous cell carcinoma, which equals the reported mean interval of $17-20$ years. ${ }^{812-14}$

In two of our patients with an oesophageal squamous cell carcinoma, a small tumour was detected in the middle third of the oesophagus, whereas in the third patient the tumour extended to both the middle and distal parts. This is in accordance with the fact that in patients with achalasia oesophageal squamous cell carcinoma occurs most frequently in the middle third of the oesophagus. ${ }^{3+7-1012}$

If chronic stagnation of food and saliva plays a major role in the cause of carcinoma, as suggested by some authors, ${ }^{7814}$ adequate relief by pneumatic dilatation would be expected to prevent the development of carcinoma. This could explain the development of oesophageal squamous cell carcinoma in patients 1 and 2 , in whom some material was still retained in the oesophagus after dilatation despite satisfactory symptomatic relief. Consequently, subjective criteria may not reflect the adequacy of dilatation therapy.

By the time symptoms of oesophageal carcinoma are evident over and above the dysphagia of achalasia, the tumour is usually advanced, resulting in a poor prognosis for the patient: $80 \%$ of patients with achalasia and carcinoma of the oesophagus have been found unsuitable for operation. ${ }^{15}$ Early detection of oesophageal squamous cell carcinoma improves the survival rate after oesophageal resection: the three-year survival after resection for stage I or II disease is $8 \% v 25 \%$ for stage III carcinoma. ${ }^{2021}$ It is, therefore, important to determine a safe period of time after achalasia has been diagnosed. In our study the interval between the diagnosis of achalasia and carcinoma was mean (range) $5 \cdot 7$ (4-8) years, suggesting a relatively long safe interval. Our results contrast, however, with those of Norton et al, who reported a range of 1.5-61 years between the diagnosis of achalasia and carcinoma. ${ }^{13}$ Unfortunately, no data on the duration of dysphagia were mentioned in this retrospective study by Norton. Therefore to detect oesophageal squamous cell carcinoma at an early stage it is still difficult to state a safe period of time after which screening should be started.

There is indirect evidence supporting endoscopic surveillance. Oesophageal squamous cell carcinoma evolves through a series of progressively dysplastic changes. ${ }^{2+26}$ According to studies of cell growth kinetics and data from mass screening programmes, progression from carcinoma in situ to invasive oesophageal squamous cell carcinoma may take three to four years. ${ }^{27}{ }^{28}$ This may support routine endoscopy as a means of detecting carcinomas at an early, potentially curable stage. In patient 2 in this study routine endoscopy detected a superficial asymptomatic oesophageal squamous cell carcinoma. In case 1 , although this patient was not asymptomatic, endoscopy revealed an early oesophageal squamous cell carcinoma. To date both patients are without signs of local recurrence or metastasis three and six years respectively after oesophageal resection.

Based on the above data, an endoscopic screening interval of two to three years seems 
safe. ${ }^{27}{ }^{28}$ Although this interval proved to be valid in our study, we cannot recommend a safe screening interval from data obtained in only three patients. Therefore, the value of endoscopic screening continues to be disputable, because its efficacy in reducing morbidity and mortality from oesophageal squamous cell carcinoma will require a larger number of patients with achalasia and a longer follow up than in our study to confirm such an effect. ${ }^{29}$

In conclusion, achalasia seems a high risk factor for oesophageal squamous cell carcinoma considering the 33 fold increased risk of developing this carcinoma in patients with achalasia. Endoscopic screening has the potential for detecting oesophageal squamous cell carcinoma in an early, non-symptomatic stage. To obtain some cost benefit, only patients fit for oesophageal resection should be screened. However, a large scale study is needed to demonstrate the benefit of endoscopic screening on the prognosis of patients with achalasia who develop oesophageal carcinoma.

l Fagge CH. A case of simple stenosis of the oesophagus, followed by epithelioma. Guy's Hosp Rep 1872; 17: 413 .

2 Kornblum K, Fischer LC. Carcinoma as a complication of achalasia of the cardia. Am F Roentgenol 1940; 43: 364-76.

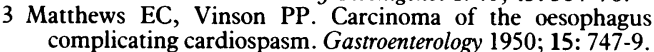

4 Camara-Lopes LH. Carcinoma of the esophagus as a complicaton of mega-esophagus: an analysis of seven cases. $A m \mathcal{F}$ Dig Dis 1961; 6: 742-56.

5 Ferreira-Santos R. Aperistalsis of the esophagus and the colon (mega-esophagus and mega-colon) etiologically related to Chagas' disease. Am $\mathcal{F}$ Dig Dis 1961; 6: 700-26.

6 Barrett NR. Achalasia of the cardia: reflections upon a clinical study of over 100 cases. BMF 1964; 1: 1135-40.

7 Belsey RH. Functional disease of the oesophagus. 7 Thorac Cardiovasc Surg 1966; 52: 164-88.

8 Just-Viera JO, Morris JD, Haight C. Achalasia and esophageal carcinoma. Ann Thorac Surg 1967; 3: 526-38.
9 Just-Viera JO, Haight C. Achalasia and carcinoma of the esophagus. Surg Gynecol Obstet 1969; 128: 1081-95.

10 Lortat-Jacob JL, Richard CA, Fekete F, Testart J. Cardiospasm and esophageal carcinoma: report of 24 cases. Surgery 1969; 66: 969-75.

11 Pierce WS, MacVaugh H, Johnson J. Carcinoma of the esophagus arising in patients with achalasia of the cardia. F Thorac Cardiovasc Surg 1970; 59: 335-9.

12 Carter R, Brewer LA III. Achalasia and esophageal carcinoma. Studies in early diagnosis for improved surgical management. Am F Surg 1975; 130: 114-20.

13 Norton GA, Postlethwait RW, Thompson WM. Esophagea carcinoma: a survey of populations at risk. South Med $\mathcal{F}$ 1980; 73: $25-7$.

14 Heiss FW, Tarshis A, Ellis FH Jr. Carcinoma associated with achalasia. Occurrence 23 years after esophagomyotomy. achalasia. Occurrence 23 ye

15 Lamb RK, Edwards CW, Pattison CW, Matthews HR. Squamous carcinoma in situ of the oesophagus in a patient with achalasia. Thorax $1985 ; 40: 795-6$.

16 O'Sullivan GC. Oesophageal motility disorders. In: Hennessy PTJ, Cuschieri A, eds. Surgery of the oesophagus. London Bailliere Tindall, 1986; 129-30.

17 Postlethwait RW. Neurogenic disturbances. In: Postlethwait RW, ed. Surgery of the esophagus. 2nd ed. Norwalk: Appleton-Century-Crofts, 1986: 97-9.

18 Carle DJ de. Achalasia. In: Jamieson GG, ed. Surgery of the oesophagus. Edinburgh: Churchill Livingstone, 1988: 465

19 Chuong JJH, DuBovik S, McCallum RW. Achalasia as a risk factor for esophageal carcinoma. A reappraisal. Dig Dis $S c i$ factor for esophageal

20 Eeftinck Schattenkerk M, Obertop H, Mud HJ, Eijkenboom WMH, Andel JG van, Houten $H$ van. Survival after resection for carcinoma of the oesophagus. Br F Surg 1987; 74: $165-8$

21 Hermanek P, Sobin LH, eds. TNM classification of malignant tumours. 4th ed. Berlin: Springer-Verlag, 1987: 41-2.

22 Cleton FJ, Coebergh JWW, eds. Cancer in the Netherlands Vol 2. Dordrecht: Kluwer Academic Publishers, 1988 : 18-9.

23 Armitage P, Berry G, eds. Statistical methods in medical research. 2nd ed. Oxford: Blackwell Scientific Publications, 1985: 438-9.

24 Correa P. Precursors of gastric and esophageal cancer. Cancer 1982; 50: 2554-65.

25 Yang CS. Research on esophageal cancer in China: a review. Cancer Res 1980; 40: 2933-44.

26 Lightdale CJ, Winawer SJ. Screening diagnosis and staging of esophageal cancer. Semin Oncol 1984; 2: 101-12.

27 Anderson LL, Lad TE. Autopsy findings in squamous-cel carcinoma of the esophagus. Cancer 1982; 50: 1587-90.

28 Guanrei Y, He H, Sungliang Q, Yuming C. Endoscopic diagnosis of 115 cases of early esophageal carcinoma. Endoscopy 1982; 14: 157-61

29 Eddy DM. The economics of cancer prevention and detection: getting more for less. Cancer 1981; 47: 1200-9.

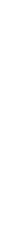

